\title{
O DEBATE SOBRE O PLC 7633/2014 NO WEBSITE VOTE NA WEB E A DELIBERAÇÃO ON-LINE
}

\author{
Daniele Ferreira Seridório, Caroline Kraus Luvizotto \\ Universidade Estadual Paulista - UNESP, Faculdade de Arquitetura, Artes e Comunicação - FAAC, Bauru/SP. \\ E-mail: seridorio@gmail.com \\ Financiamento: FAPESP - Fundação de Amparo à Pesquisa do Estado de São Paulo
}

\begin{abstract}
RESUMO
A expansão e inerência do ambiente on-line possibilitaram às assembleias de praça pública alcançar fóruns, sites e outras plataformas digitais de interação. Para o processo deliberativo foi cunhado um novo termo, a deliberação on-line. Neste contexto, este artigo pretende refletir sobre a deliberação on-line e os processos comunicativos e interativos que a envolvem para analisar a inclusividade no website Vote na Web e concluir a respeito do seu potencial deliberativo. Para a análise empírica escolhemos o debate em torno do projeto de lei complementar 7633/2014, que diz respeito ao parto humanizado. Apesar das limitações do website, fazendo parte da cultura da participação, acreditamos que o Vote na Web possa ser um passo de participação cidadã para um posterior engajamento cívico, por isso, pensamos que iniciativas como essa são fundamentais no exercício da cidadania e na discussão política no Brasil.
\end{abstract}

Palavras-Chave: Participação Política. Deliberação On-line. Inclusividade. Vote na Web.

\section{THE DEBATE ABOUT THE PLC 7633/2014 AT THE WEBSITE VOTE NA WEB AND THE ON-LINE DELIBERATION}

\begin{abstract}
The expansion and the inherence of the cyberspace helped the public places assemblies to reach forums, sites and other digital interaction platforms. To the deliberative term it was built a new perspective, the on-line deliberation. In this context, this article aims to discuss about on-line deliberation and the communicative and interactive process that it involves, to analyses the inclusivity at Vote na Web and conclude about it deliberative potential. To the analyses we choose the debate about the law project 7633/2014, which talks about humanitarian labor. Even though the website's limitations, being part of the participation culture, we believe that Vote na Web can be one step into the citizen participation of the way to civil engagement, that's why, we think initiatives like that are fundamental in the citizen exercise and in the political discussion in Brazil.

Keywords: Political Participation. On-line Deliberation. Inclusivity. Vote na Web.
\end{abstract}




\section{INTRODUÇÃO}

Desde 2014 tramita na Câmara dos Deputados o projeto de lei complementar (PLC) 7633/2014, que dispõe da humanização do atendimento à gestante e ao neonato, estabelecendo diretrizes para o atendimento médico durante a gestação e após o nascimento do bebê. $O$ texto, ainda prevê coibir a violência obstétrica. Neste cenário, é fundamental ouvir a voz das mulheres em relação a essas medidas que diretamente lhe são destinadas. No site da Câmara dos Deputados, o PLC 7633/2014 entrou para participação popular por uma enquete - os usuários poderiam optar se concordavam ou não com a proposta. O site traz a seguinte pergunta "Você concorda com a proposta que limita o número de cesarianas no país à média recomendada pela Organização Mundial de Saúde (OMS), atualmente de 15\% dos partos?". A enquete ainda está ativa, mas até 12 de março de 2015, mais de 58\% afirmaram que sim, 40\% que não e $1 \%$ não tem opinião formada.

Apesar de a enquete ser uma forma de participação popular, não é possível ter dados a respeito de quantas mulheres votaram, e o espaço destinado aos comentários é pouco interativo, não permitindo que um usuário responda ao outro, propondo um debate. Então, para conhecer a percepção das mulheres e conhecer argumentos em torno deste debate faz-se necessário analisar a discussão em outra plataforma.

Neste contexto, temos o website Vote na $W_{e} b^{1}$, que traz os projetos que estão em tramitação nas assembleias legislativas para votação popular, propondo um espaço de debate e com dados a respeito do gênero, da idade e a qual unidade da federação reside o usuário que votou em determinado fórum. Uma das principais características do Vote na Web são os resumos apresentados, formulados por analistas - a partir do texto do projeto de lei original - que buscam traduzir os termos utilizados para uma linguagem mais próxima a do público. Quando a lei passa por votação na Câmara e no Senado o site apresenta uma comparação entre o voto dos legisladores e dos usuários. Outros aspectos da arquitetura do referido site podem ser citados, como por exemplo, a divisão dos projetos de lei apresentados em categorias, como, economia, saúde, trabalho, cidades, cultura, esporte, transporte, entre outras. No site, também há duas ferramentas de busca, por filtros pré-estabelecidos, ou por palavras-chave.

A análise da inclusividade da mulher na votação do referido website traz resultados relevantes para discussão a respeito da comunicação mediada pelo computador como meio para participação política e estabelecimento de processo deliberativos on-line. "Em uma sociedade na qual a informação se torna essencial para a criação e manutenção de estratégias que visem a uma sociedade mais justa e à efetivação da democracia, a internet se apresenta como um dos principais canais de comunicação" entre os atores sociais (ROTHBERG et al, 2014, p. 231).

Neste sentido, este artigo pretende refletir sobre a deliberação on-line e os processos comunicativos e interativos que a envolvem para analisar a inclusividade no website Vote na Web e concluir a respeito do seu potencial deliberativo. Para a análise empírica escolhemos o debate em torno do projeto de lei complementar 7633/2014, que diz respeito ao parto humanizado.

\section{METODOLOGIA}

Esta pesquisa caracteriza-se por ter como vertente metodológica uma abordagem qualiquantitativa. Fazemos uso de métodos descritivos característicos da abordagem quantitativa para apresentar de forma gráfica e estruturada os dados produzidos. Elementos que não estavam adequados para uma abordagem quantitativa foram direcionados para a abordagem qualitativa. Inicialmente foram construídos os conceitos de deliberação e deliberação on-line. A partir da compreensão desses conceitos foi efetuada a descrição do website VotenaWeb e a análise do debate em torno do projeto de lei complementar 7633/2014.

\footnotetext{
${ }^{1}$ Disponível em www.votenaweb.com.br
} 
A coleta de dados foi feita de maneira sistemática no dia 18 de janeiro de 2015. As informações que procuramos foram as seguintes quantidades: mulheres que votaram; homens que votaram; habitantes de cada um dos estados de federação que votaram; e usuários por de cada faixa etária que votaram. Consideramos as faixas de 0 a 19 anos; 20 a 34 anos; 35 a 59 anos; 60 anos ou mais. Depois de coletados, os dados foram organizados em tabelas e gráficos e comparados aos números da pesquisa Censo 2010, realizada pelo Instituto Brasileiro e Geografia e Estatística (IBGE).

\section{RESULTADOS E DISCUSSÃO}

Essa expansão e inerência do ambiente on-line chegaram às assembléias de praça pública e levaram-nas para fóruns, sites e outras plataformas digitais de interação. Para o processo deliberativo (HABERMAS 1997; DRYZEK, 2007) foi cunhado um novo termo, a deliberação on-line (JANSSEN e KIES, 2005; SAMPAIO, et al, 2012) e emergiram pesquisadores e estudos que concentram seus esforços em discutir e analisar a qualidade deliberativa dessas arenas on-line de comunicação, participação e interação. Essas arenas virtuais, além de proporcionarem espaço para o debate, dão visibilidade para questões que antes encontravam pouco espaço nas mídias tradicionais, ou que eram discutidas com baixa pluralidade de opiniões e atores.

Com a internet as formas de comunicação e consumo de informação se modificaram e deixaram de ser unilaterais - marca dos meios de comunicação de massa - sendo mais participativas e democráticas. Devido à interatividade, com a criação das redes sociais e blogs, por exemplo, a internet proporciona aos seus usuários a capacidade de produzir informação, ao invés de somente consumi-la. Observa-se que as plataformas on-line da web 2.0 foram tomadas por discussões e debates dos mais variados temas. Entende-se que, mesmo que de maneira limitada devido à sua infraestrutura de conectividade e a aspectos relativos como a arquitetura da informação do website, como por exemplo a acessibilidade e a usabilidade, a internet possibilita participação e interação real entre seus usuários, sendo uma forma de comunicação rápida, prática e sem barreiras geográficas e temporais.

Potencializada a participação, a deliberação também alcançou outros níveis com o advento da internet. Os textos de Habermas $(1997,2005)$ representam a base da discussão sobre deliberação e as relações sociais que a envolvem, já que esse filósofo propõe um modelo de democracia que ao mesmo tempo em que não abdica de uma interação forte entre cidadãos e representantes para a formação da opinião, não deixa de reconhecer direitos, liberdades e reivindicações individuais (SAMPAIO, et al, 2012).

O projeto de lei complementar (PLC) $7633 / 2014^{2}$ dispõe sobre a humanização do atendimento à gestante e ao neonato e estabelece diretrizes para o atendimento médico durante a gestação e após o nascimento do bebê. $O$ texto, ainda prevê coibir a violência obstétrica. $A$ figura 1 apresenta a votação geral do PLC 7633/2014 no website Vote na Web:

\footnotetext{
${ }^{2}$ Informações sobre o PLC 7633/2014 no Vote na Web estão disponíveis em http://www.votenaweb.com.br/projetos/plc-7633-2014
} 
Votos dos cidadãos
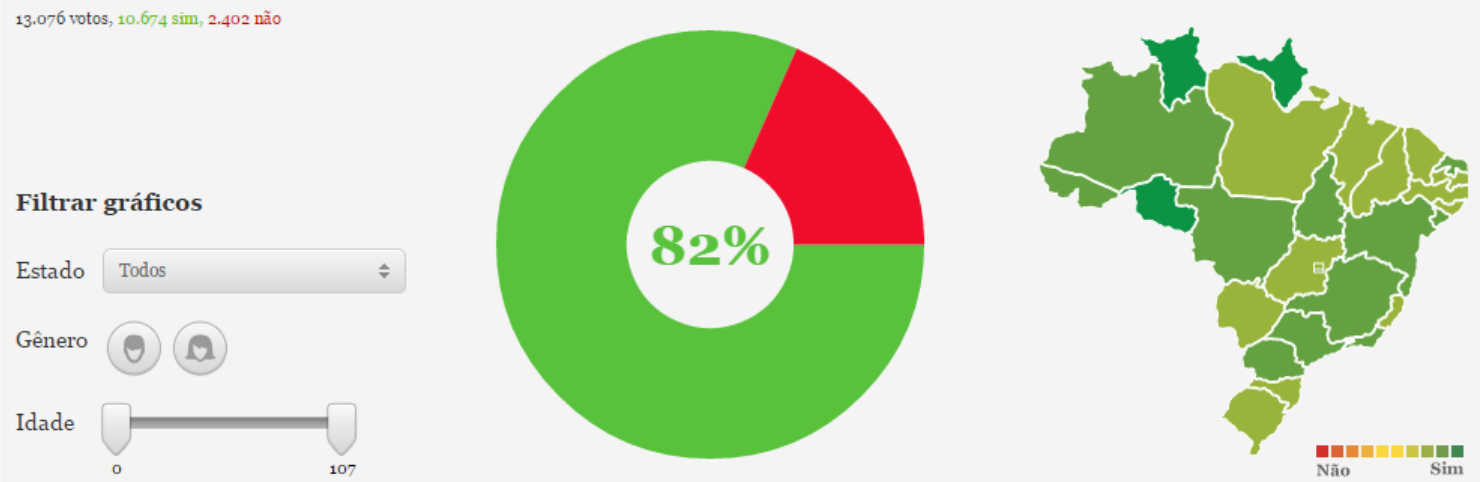

Classificação do cidadão para este projeto

527 classificaçōes

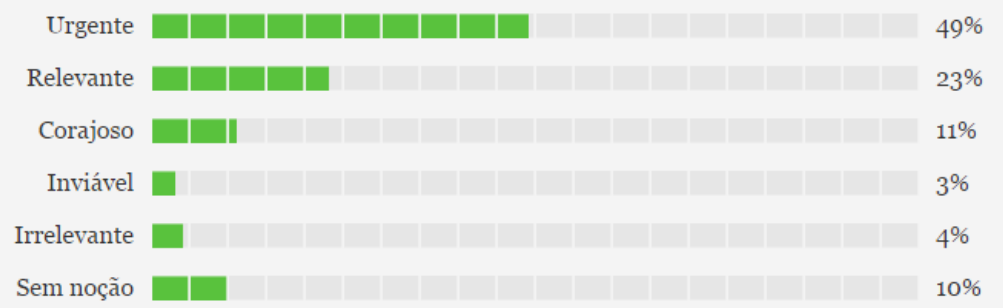

Figura 1. Votação geral do PLC 7633/2014 no website Vote na Web.

Fonte: Vote na Web/2015

Apenas $34 \%$ dos usuários que votaram se identificaram como mulher, $52 \%$ declaram-se homens e $14 \%$ não escolherem entre as opções possíveis - homem ou mulher (gráfico 1).

Gráfico 1. Inclusividade na votação avaliada

Fonte: Autoria Própria/2015

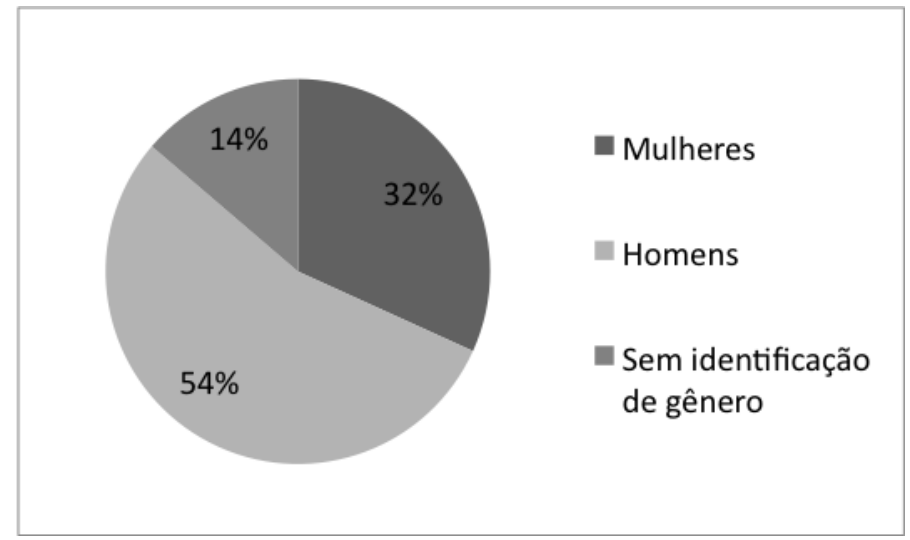

Quando comparamos esse resultado aos dados da pesquisa Censo de 2010, realizada pelo IBGE, percebemos que esses números indicam baixa inclusividade das mulheres na votação. Dos mais de 190 milhões de habitantes do Brasil - residentes em domicílios - 97.348 .809 são mulheres (gráfico 2). 
Gráfico 2. Dados do IBGE

Fonte: Autoria Própria/2015

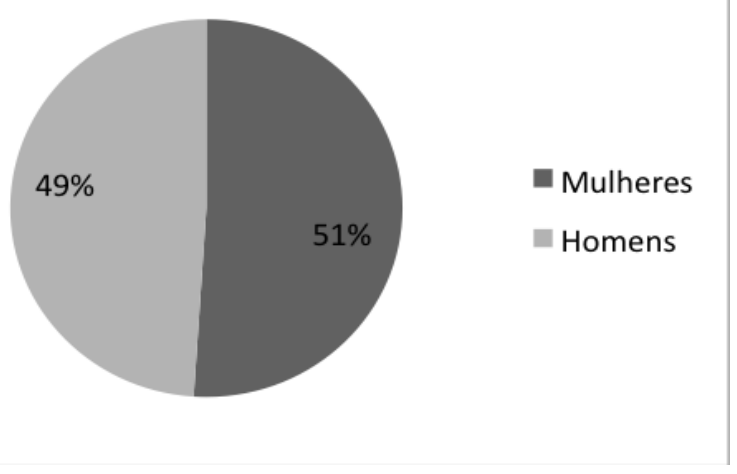

Mesmo que todos os usuários que não escolheram opção de gênero fossem mulheres a taxa de inclusão ainda não atingiria um parâmetro ideal frente à realidade nacional, porém se aproximaria muito disso $-48 \%$.

Ainda podemos discutir o reflexo desta baixa inclusão no resultado da votação (gráfico 3). Quando separamos os resultados entre os votantes que se consideram homens (gráfico 4) e entre os votantes que se consideram mulheres (gráfico 5) temos os seguintes resultados:

Gráfico 3. Votação do projeto analisado considerando todos os usuários que votaram Fonte: autoria própria/2015

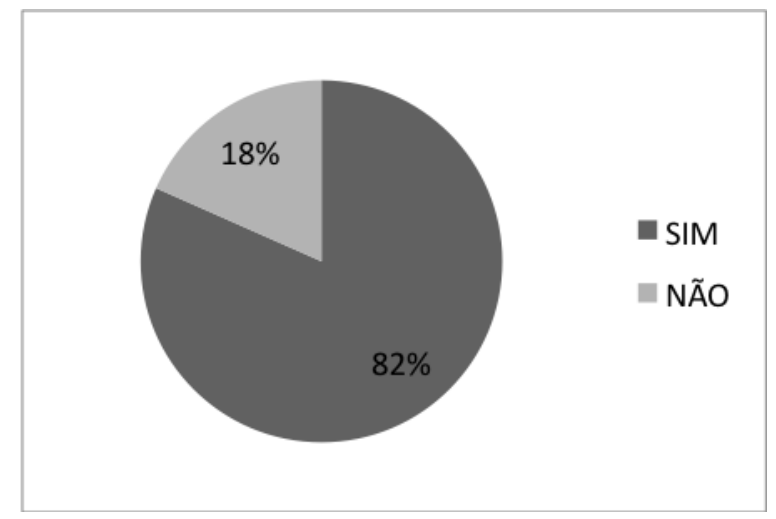

Gráfico 4. Votação do projeto analisado considerando somente os usuários homens que votaram. Fonte: autoria própria/2015

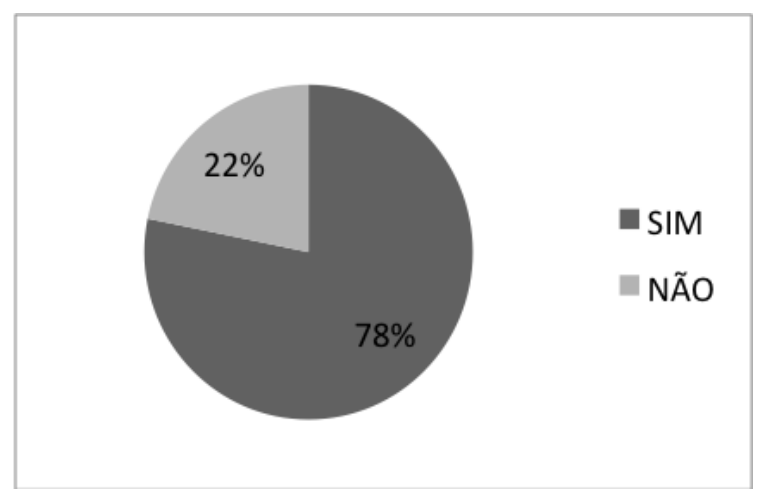


Gráfico 5. Votação do projeto analisado considerando somente os usuários mulheres que votaram.

Fonte: autoria própria/2015

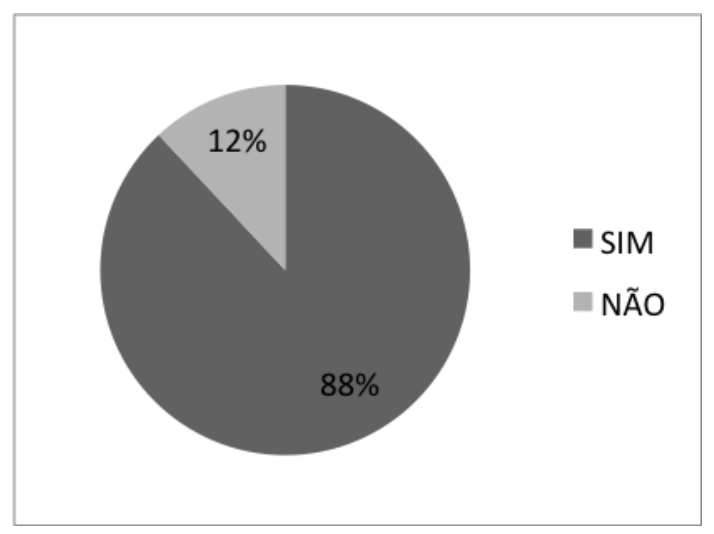

Isso mostra que na discussão de um projeto de lei que atinge diretamente às mulheres, se somente homens ou mulheres estivessem votando, a diferença entre os que optaram pelo "sim" ou pelo "não" chega a $10 \%$. Outro resultado relevante a ser considerado é a grande porcentagem de usuários que não se identificaram como homens ou como mulheres $-14 \%$. A própria pesquisa do IBGE não permite outra identificação.

Outro resultado analisado foi a inclusividade por estados da federação. Nesta categoria, observamos que quatro estados tiveram a mesma participação percentual na votação e na composição da população brasileira, eles são: Paraíba (2\%); Paraná (5\%); Santa Catarina (3\%); e Sergipe (1\%). O estado com a menor inclusividade é a Bahia; sua população representa $7 \%$ dos habitantes no país, porém na votação no Vote na web, representa apenas $2 \%$ dos usuários. $\mathrm{E}$ as unidades da federação que desequilibram a votação - ou seja, tem maior representatividade no site - são: São Paulo; Rio de Janeiro e Distrito Federal.

O número de usuários que não identificaram o gênero foi o mesmo que não identificou o estado. Muito estados não chegam a atingir $1 \%$ de participação nem no vote na Web e nem na população brasileira, por isso, consideramos para essas unidades da federação percentual menor que 0 .

\section{CONCLUSÕES}

O desenvolvimento das tecnologias de informação e comunicação e a própria configuração em rede da internet promoveram profundas mudanças na sociedade, desde a própria reorganização do capital para bens imateriais de informação e conhecimento - fenômeno que caracteriza a Sociedade da Informação - até a maneira como os indivíduos se comunicam e produzem mídia. A sociedade apropriou-se dessas tecnologias e formou-se uma rede que utiliza esse aparato tecnológico para interagir, comunicar-se e participar.

Concluímos a partir da nossa análise que baixa inclusividade é um reflexo de dois principais fatores: inclusão digital no Brasil; diversidade e baixa aderência do website analisado. A inclusão digital é um desafio para o Brasil, e não podemos considerar somente a quantidade de aceso, mas as habilidades necessárias para manusear um computador e utilizar a internet como um meio de participação política.

Dados do Comitê Gestor de Internet mostram que, em 2013, 48\% dos lares brasileiros tinham acesso à internet. A maior parcela da população não é, portanto, incluída nas discussões que ocorrem na internet. Por mais que a internet seja uma plataforma com potencial para participação política e deliberação, a pequena penetrabilidade desse meio nos lares brasileiros não permite que esse potencial seja transformado em ações efetivas. 
Enquanto computadores com internet não chegam aos domicílios, observa-se no Brasil um fenômeno de grande adesão aos dispositivos móveis. Dados da Agência Nacional de Telecomunicação (Anatel) mostraram que o Brasil fechou o ano de 2013 com 103,11 milhões de acessos à banda larga móvel, e de janeiro a dezembro daquele ano a quantidade de acesso à rede $3 \mathrm{G}$ cresceu mai de $75 \%$ e a de $4 \mathrm{G}$ mais de $8 \%$. Então, para que os sites que propõem um espaço de participação e deliberação política sejam mais inclusivos, é preciso explorar plataformas compatíveis aos dispositivos móveis. A empresa webcitizen desenvolveu, a partir do Vote na Web, o aplicativo para dispositivos móveis "Papo de Bouteco".

A análise deste ambiente de comunicação é fundamental para o fomento da discussão de uma democracia mais igualitária. Afinal, são discutidos projetos que podem vir a se tornar lei no país. Ademais, o Vote na Web representa um ambiente comunicacional independente, onde o fluxo parte da esfera civil, debatendo temas que em uma esfera pública eram de discussão exclusiva dos estadistas.

\section{REFERÊNCIAS}

Agência Nacional de Telecomunicações. Brasil fecha 2013 com 271,10 milhões de acessos móveis. Recuperado em: 26 de fevereiro, 2015 de: http://www.anatel.gov.br/ Portal/exibirPortalNoticias. do $?$ acao=carregaNoticia\&codigo $=32359$.

Brasil. Diário Oficial da União. http://www.jusbrasil.com.br/diarios/82815223/dou-secao-1-07-012015-pg-38. 2005. Recuperado em: 11 de março, 2015

Comitê Gestor de Internet. Pesquisa sobre o Uso das Tecnologias de Informação e comunicação no Brasil. http://cgi.br/media/docs/publicacoes/2/TIC_DOM_EMP_2013_livro_eletronico.pdf. 2013. Recuperado em: 26 fevereiro, 2015.

DRYZEK, J. Theory, Evidence and the Tasks of Deliberation. In: Deliberation, Participation and Democracy: Can the people govern? Organização: Shawn Rosenberg. Nova lorque: Palgrave Macmillan, 2007.

Escola nacional de Saúde Pública. Pesquisa Nascer no Brasil. http://www6.ensp.fiocruz.br/ nascerbrasil/principais-resultados2/. 2014. Recuperado em: 11 março, 2015.

HABERMAS, J. Concluding Comments on Empirical Approaches to Deliberative Politics. In: Acta Politica, vol. 40, 384-392, 2005. https://doi.org/10.1057/palgrave.ap.5500119

Direito e Democracia: entre facticidade e validade. Rio de Janeiro, Brasil: Tempo Brasileiro, 1997.

Instituto Brasileiro de Geografia e Estatística. Censo 2010. http://7a12.ibge.gov.br/vamosconhecer-o-brasil/nosso-povo/caracteristicas-da-populacao. Recuperado em 24 de fevereiro, 2015.

JANSSEN, D.; KIES, R. Online Forums and Deliberative Democracy. Acta Politica, vol. 40, p. 317-335, 2005. https://doi.org/10.1057/palgrave.ap.5500115

ROTHBERG, D. et al. As revoltas e seu impacto sobre a comunicação pública: o potencial do Observatório Participativo da Juventude In: Liinc em Revista, vol. 10, no 1, pp. 227-240, 2014. 
SAMPAIO, R. C., et al. Como avaliar a deliberação online? Um mapeamento de critérios relevantes. In: Opinião Pública, vol. 18, no 2, pp. 470-489, 2012. 